\title{
ВОПРОСЫ СОВЕРШЕНСТВОВАНИЯ КОНТРОЛЬНЫХ МЕРОПРИЯТИЙ ПО КУРСУ «ОСНОВЫ СЕТЕВЫХ ТЕХНОЛОГИЙ»
}

\section{IMPROVEMENT ISSUES OF CONTROL ACTIVITIES FOR THE COURSE "FUNDAMENTALS OF NETWORK TECHNOLOGIES"}

\section{S. Tulinov}

E. Golubkova A. Kruglov

Summary: This article examines the composition and purpose of the course «Fundamentals of network technologies» for RTU MIREA students, reveals its relevance and the main advantages of studying. To improve the control activities for the course and rationalize the work of the teacher and students, the authors redesigned the existing materials and created their own set of questions.

A new algorithm for setting off the practical works is presented in detail, including the processes of motivation and control of student learning in the semester.

Solutions are proposed to improve the quality of control activities and the number of students who reach the required level of competence in the field of principles of construction and administration of computer networks.

Keywords: fundamentals of network technologies, practical work, quality of the educational process, Cisco NetAcad. $\mathrm{y}$ чебным планом для студентов 3 курса Института ИТ РТУ МИРЭА предусмотрен двухсеместровый курс «Основы сетевых технологий» объемом 144 акад. час., каждая часть изучается в течении одного семестра. В состав курса входит 21 тема лекций и 21 практическая работа форма промежуточной аттестации в каждом семестре - зачет. Начиная с 2016-го года обучение проходит более 2500 студентов.

В основе курса лежит международная образовательная программа CCNA R\&S (Introduction to Networks и Routing and Switching Essentials) сетевой академии Cisco Netacad, которая объединяет партнерские учебные заведения по всему миру [1]. Программа постоянно совершенствуется для актуализации востребованных компетенций в таких сферах, как построение локальных сетей, сетевое администрирование, сетевая безопасность. Для всех студентов академии бесплатно предоставляется разработанный компанией Cisco симулятор Packet Tracer (РТ) - это многофункциональная программа моделирования сетей, которая позволяет студентам экспериментировать с поведением сети и оценивать возможные
Тулинов Сергей Владимирович

Руководитель сетевой академии Сisco, РТУ МИРЭА

tulinov@mirea.ru

Голубкова Екатерина Михайловна

Инструктор сетевой академии Cisco, РТУМИРЭА

golubkova@mirea.ru

Круглов Анатолий Михайлович

Инструктор сетевой академии Cisco, РТУ МИРЭА kruglov@mirea.ru

Аннотация: В настоящей статье рассмотрен состав и назначение курса «0сновы сетевых технологий» для студентов РТУ МИРЭА, раскрывается его востребованность и основные преимущества изучения. Для совершенствования контрольных мероприятий по курсу и рационализации работы преподавателя и студентов авторами проводится переработка имеющихся материалов и создание собственного банка вопросов.

Подробно представлен новый алгоритм защиты практических работ, включающий в себя процессы мотивации и контроля обучения студентов в семестре.

Предложены решения для повышения качества контрольных мероприятий и числа студентов, достигающих необходимого уровня компетенций в области принципов построения и администрирования компьютерных сетей.

Ключевые слова: основы сетевых технологий, практическая работа, качество образовательного процесса, Cisco NetAcad.

сценарии, а также облегчает преподавание и изучение сложных технологических принципов [2].

Немаловажной частью курса является самостоятельная работа студентов, включающая в себя изучение теоретического материала и освоение принципов работы ряда сетевых технологий благодаря практике конфигурирования реального сетевого оборудования и работы в программе РТ для эмуляции и проектирования любой сетевой инфраструктуры.

О востребованности курса CCNA R\&S свидетельствует тот факт, что он преподается в 180 странах и охватывает 7,8 миллионов студентов. После прохождения этого курса студенты приобретают компетенции сетевых технических специалистов и сетевых администраторов. В рамках курса студенты учатся самостоятельно создавать простые локальные сети, получают практические знания о схемах IP-адресации, базовых понятиях сетевой безопасности и настройке основных параметров маршрутизаторов и коммутаторов [3]. 
Рассматриваемый курс готовит студентов к сдаче сертификационного экзамена CCNA (200-301). Многолетняя практика показывает, что обладатели такого сертификата имеют существенные преимущества на конкурентном рынке труда.

В образовательном процессе контрольные мероприятия служат важным показателем достижения необходимого уровня компетенций. Проблематика их совершенствования рассмотрена, в частности, в $[4,5,6]$. В [7] упор делается на проведение сравнительного анализа оценок после тестирования двух групп студентов и применение методик, включающих практику самообучения и повышающих качество образования. В [8] предлагается подход, состоящий в применении регулярных письменных экспресс-опросов без предварительного предупреждения, что побуждает студентов при изучении курса активизировать самостоятельную подготовку и самообучение.

Авторами внедрена следующая структура прохождения курса «Основы сетевых технологий», рисунок 1.

Стрелками на рисунке 1 показано взаимодействие работы преподавателя и студента, которое состоит в:

- изучении студентами лекционного материала по курсу CCNA R\&S, к которому они имеют доступ через портал сетевой академии Cisco Netacad;

- в просмотре видео-лекций по всем темам двухсеместрового курса, доступные в интернет-лаборатории Ims.termilab.ru [9] и позволяющие студентам более полно подготовиться к защите практических работ и зачету;

- доступе к удаленному стенду в интернет-лаборатории Termilab для выполнения практических за- даний с использованием комплексов инфокоммуникационного оборудования;

- отчете о проделанных практических заданиях в виде проекта в симуляторе РТ с проверкой теоретических знаний и практических навыков по главам курса;

- выполнении типового итогового задания на зачете.

При защите отчета по практическим работам особое внимание уделяется последовательности конфигурации сетевых сегментов, умению идентифицировать ошибки конфигурации различных устройств. В целом, в осеннем семестре на 3-м курсе студентами изучается 11 тем и предлагается выполнение 9 практических работ. В весеннем семестре - 10 тем и 12 практических работ, которые углубляют теоретические сведения предыдущего семестра.

Поскольку курс является многопоточным и преподаватели одновременно обучают сотни студентов, то основная проблематика, рассматриваемая в настоящей статье, - это улучшение этапа «контроль» при защите работ. При сохранении элементов традиционных форматов предлагаются дополнения, основанные на следующих подходах:

Прежде всего необходимо рационализировать защиту практических работ и повысить эффективность использования бюджета времени непосредственного общения студента с преподавателем в аудиторном или дистанционном режимах. Это было реализовано с помощью составления тестовых вопросов по каждой практической работе и теории из соответствующей главы курса для второго семестра. Всего было составлено 550 тесто-

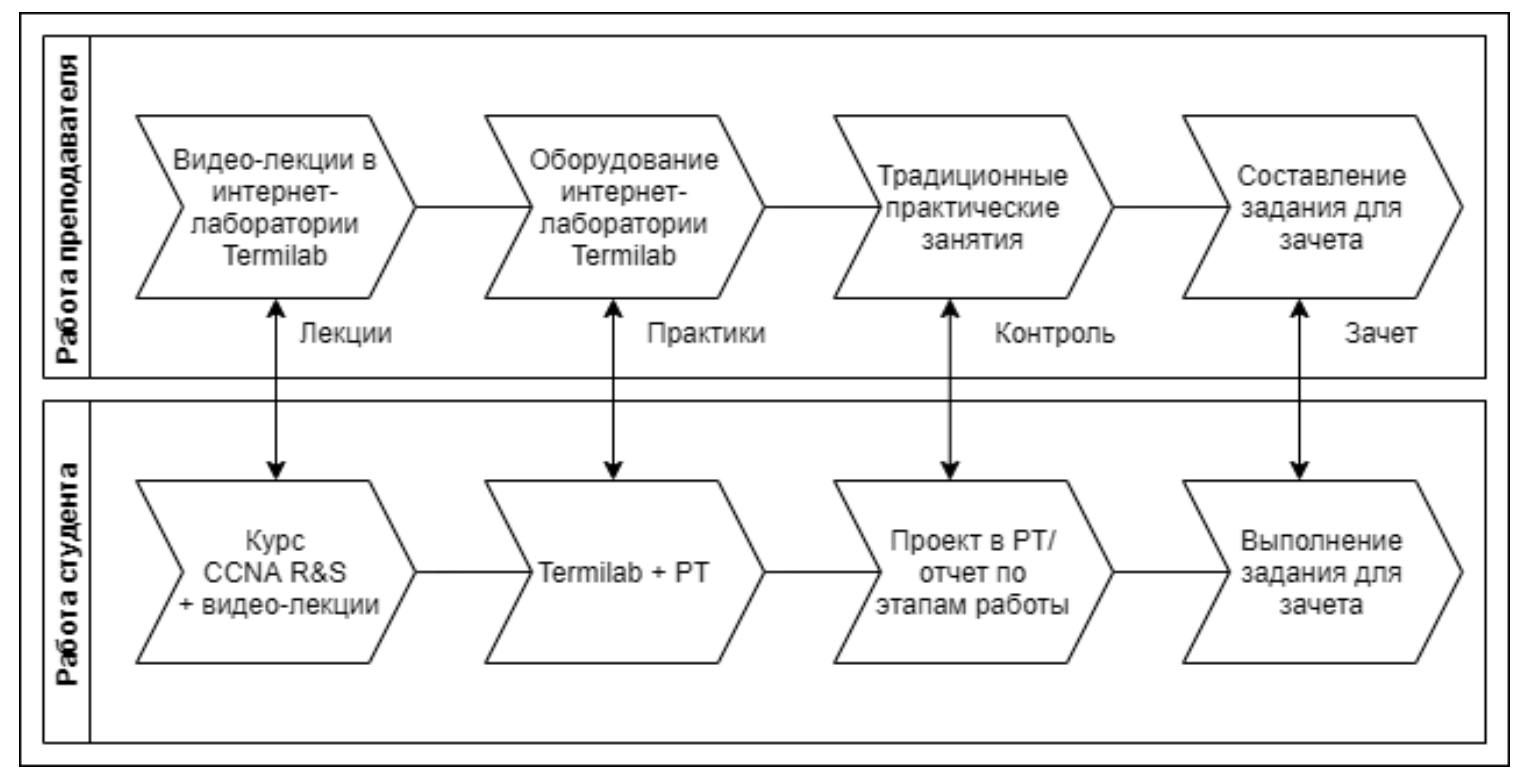

Рис. 1. Структура прохождения курса «Основы сетевых технологий» [Разработано авторами] 
вых вопросов для 12-ти практических работ.

Кроме того, были существенно переработаны задания по практическим работам. Студентам предстоит проверить, насколько хорошо они запомнили конфигурационные команды, т.к. в новой редакции заданий они были по больше части удалены. Это сделано с целью мотивации студентов внимательнее изучать теоретическим материал и обращаться к другим ресурсам курса для достижения требуемого уровня компетенций.

Еще одним методом контроля является индивидуализация заданий, которые теперь выполняются по вариантам. В качестве примера такой индивидуализации можно привести необходимость указания фамилии студента в имени сетевого устройства, а также сетевая конфигурация, настраиваемая в зависимости от номера студента в группе. Данные контрольные мероприятия позволят выяснить, действительно ли задание выполнено самостоятельно.

Алгоритм защиты теперь выглядит следующим обра3ом:

1. Прежде всего каждому студенту необходимо показать результат выполнения практической работы, которым может являться: настроенная топология сети в симуляторе РТ, расчет и скриншоты основных этапов работы. Также можно отобразить результаты задания непосредственно на реальном оборудовании в лаборатории;

2. После проверки индивидуального задания необходимо выполнить тестовый вариант с вопросами. Так как во 2-й части курса всего 12 практических работ (при этом две их них тесно связаны), то было решено составить для каждой практической работы по 10 различных вариантов;

3. Количество вопросов по каждой практической работе устанавливается равным 5, охватывающим основные конфигурационные команды и теоретические вопросы по главе, к которой относится данная работа. Для успешной сдачи практической работы необходимо ответить на 3 вопроса из 5, не обращаясь к материалам курса. Каждый вопрос имеет только один правильный ответ из четырех. Студенту предлагается самостоятельно решить свой вариант, но допускается уточнение вопроса у преподавателя в случае затруднения восприятия формулировки вопроса.

При хорошей подготовке студента такие правила приема рационализируют и ускоряют процесс защиты.

Если студент не смог с первой попытки ответить хотя бы на 3 вопроса из 5, то на этом этапе работа не засчитывается и студенту предлагается сдать ее на следующем занятии после устранения пробелов в подготовке.
Допускается сдача сразу нескольких практических работ на одном занятии. Хорошая подготовка студентов и защита работы поощряется в виде дополнительных баллов на зачете (2 балла за 1 защищенную работу).

Такая организация контрольных мероприятий для процесса промежуточной аттестации потребовала существенного расширения фонда оценочных средств (ФОС). С этой целью авторами был разработан набор из 550 вопросов.

Здесь следует отметить, что для разработки ФОС были задействованы, в основном, необходимые теоретические сведения по конфигурационным командам и результаты их выполнения. Кроме того, были добавлены вопросы, которые присутствуют в электронном курсе CCNA R\&S в контрольных работах и в различных источниках, где собраны проверочные материалы по главам курса.

Проведенный анализ с целью развития дополнения имеющихся контрольных материалов позволил выявить темы, вызвавшие наибольшие затруднения при выполнении практических работ. Это потребовало существенного увеличения числа контрольных вопросов относительно присутствующих в официальном курсе. Большая часть вопросов из ФОС была разработана авторами для того, чтобы избежать возможности поиска студентами готовых решений в различных источниках.

Сводная информация по составу вопросов из ФОС представлена в табл.1, а пример разработанного авторами вопроса - на рисунке 2.

Таблица 1.

Сводная информация по составу вопросов из ФОС

\begin{tabular}{|l|c|c|}
\multicolumn{1}{|c|}{ Тема курса } & $\begin{array}{c}\text { Имеющиеся } \\
\text { вопросы }\end{array}$ & $\begin{array}{c}\text { Вопросы, } \\
\text { разработанные } \\
\text { авторами }\end{array}$ \\
\hline 1. Концепция маршрутизации & 0 & 50 \\
\hline 2. Статическая маршрутизация & 8 & 42 \\
\hline 3. Динамическая маршрутизация & 15 & 35 \\
\hline 4. Коммутируемые сети & 8 & 42 \\
\hline 5. Конфигурация коммутатора & 1 & 49 \\
\hline 6. Сети VLAN & 21 & 79 \\
\hline 7. Списки контроля доступа & 10 & 40 \\
\hline 8. DHСР & 12 & 38 \\
\hline 9. Преобразование NAT для IPv4 & 18 & 32 \\
\hline $\begin{array}{l}\text { 10. Устройства - обнаружение, } \\
\text { управление и обслуживание }\end{array}$ & 16 & 34 \\
\hline
\end{tabular}

Таким образом, удалось получить непересекающийся спектр инвариантных заданий, отражающий все клю- 
1. На маршрутизаторе ввели следующую конфигурацию:

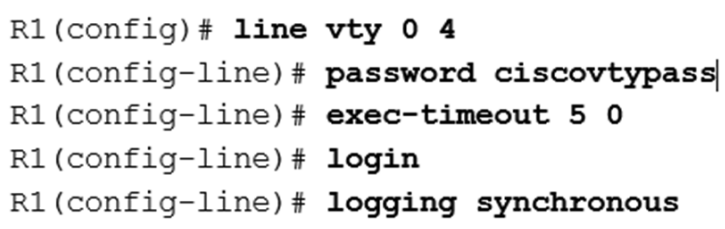

Отсутствие какой команды позволит войти на маршрутизатор без запрашивания пароля?

A - logging synchronous

$B$ - password ciscovtypass

$\mathrm{C}-\operatorname{login}$

D - exec-timeout 50

Рис. 2. Пример тестового вопроса из ФОС [Разработано авторами]

чевые тематики курса, которые предлагаются для студентов, выполнивших индивидуальную практическую работу дома или в лаборатории.

Вся информация о порядке приема и защиты практических работ заблаговременно публикуется на сайте курса [10] и доводится до студентов посредством других каналов коммуникаций.

После апробации ФОС было проведено анкетирование, которое показало оценку студентов данных контрольных мероприятий и позволило выявить преимущества и недостатки для того, чтобы продолжить совершенствовать методы обучения в рамках курса «Основы сетевых технологий».

Первый опыт внедрения рассмотренных контрольных мероприятий показал положительные результаты. Очередная задача состоит в их анализе и совершенствовании, в том числе по итогам опроса студентов с помощью анкетирования.

\section{Зак^ючение}

Для повышения качества учебного процесса по курсу «Основы сетевых технологий» было разработано комплексное решение, основанное на индивидуализации практических работ для студентов и создания большого количества тестовых вариантов вопросов теоретического и практического характера.

В статье представлены ключевые правила и требования по приему практических работ, а также приведена сводная информация по составу переработанных авторами вопросов из ФОС. Все решения являются основным результатом работы авторов и позволяют рационализировать бюджет времени преподавателя и студентов.

В конце каждого семестра предусмотрено проведение анкетирования, позволяющего оценить результативность новой методики. Анализ этих результатов представляет направление дальнейших исследований.

ЛИТЕРАТУРА

1. Одом Уэнделл. Официальное руководство Сіsсо по подготовке к сертификационным экзаменам CCENT/CCNA ICNDI 1 00-101, акад. изд.: Пер. с англ. М.: 000 «И.Д. Вильяме», 201 5. - 912 с.: ил. - П арал. тит. англ.

2. Cisco Packet Tracer [Электронный ресурс] - Режим доступа: https://www.cisco.com/c/ru_ua/training-events/netacad/training-courses/cisco-packet-tracer. html (дата обращения: 20.12.19)

3. Cisco Networking Academy [Электронный ресурс] - Режим доступа: https://www.netacad.com/ru (дата обращения: 20.12.19)

4. Мерлина Н.И., Селиверстова Л.В., Ярдухина С.А. Балльно-рейтинговая система оценки качества успеваемости студентов // БГЖ. 2015. №3 (12). - Режим доступа: https://cyberleninka.ru/article/n/ballno-reytingovaya-sistema-otsenki-kachestva-uspevaemosti-studentov (дата 0бращения: 24.07.2020).

5. Баляева С.А. Развитие дистанционной образовательной среды в морском университете // Colloquium-journal. 2019. №3-3 (27). - Режим доступа: https:// cyberleninka.ru/article/n/razvitie-distantsionnoy-obrazovatelnoy-sredy-v-morskom-universitete (дата обращения: 24.07.2020).

6. Папуткова Г.А., Седых Е.П., Орлова 0.А. Проектирование системы независимой оценки качества деятельности студентов в процессе промежуточной аттестации // Современные проблемы науки и образования. - 2015. - № 4. - Режим доступа: http://www.science-education.ru/ru/article/view?id=21240 (дата обращения: 24.07.2020).

7. Цибизова Т.Ю., Постников В.М., Спиридонов С.Б. Анализ влияния технологий лекций-визуализаций на результаты контрольных мероприятий по учебным дисциплинам // ПНи0. 2018. №3 (33). - Режим доступа: https://cyberleninka.ru/article/n/analiz-vliyaniya-tehnologiy-lektsiy-vizualizatsiy-na-rezultatykontrolnyh-meropriyatiy-po-uchebnym-distsiplinam (дата обращения: 24.07.2020).

8. Горшкова 0.0. Совершенствование контроля знаний как условие формирования познавательного потенциала студента // Фундаментальные исследова- 
ния. - 2005. - № 3. - Режим доступа: http://www.fundamental-research.ru/ru/article/view?id=5889 (дата обращения: 24.07.2020).

9. TERMILAB - Интернет-лаборатория [Электронный ресурс] - Режим доступа: https://lms.termilab.ru/ (дата обращения: 1.09.2020).

10. Основы сетевых технологий для студентов РТУ МИРЭА [Электронный ресурс] - Режим доступа: termilab.ru/mirea (дата 0бращения: 1.09.2020).

() Тулинов Сергей Владимирович (tulinov@mirea.ru), Голубкова Екатерина Михайловна (golubkova@mirea.ru),

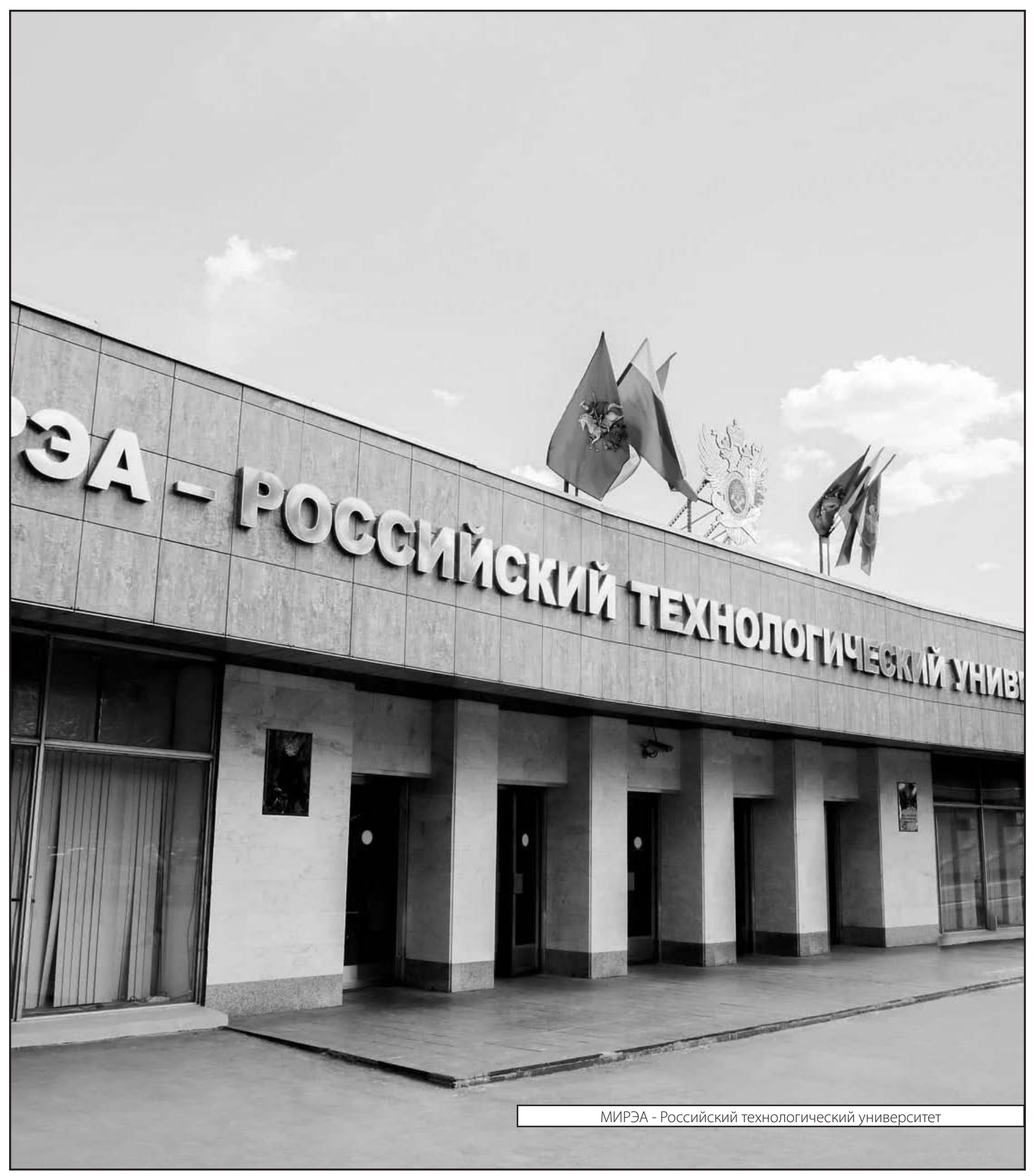

